\title{
Lesiones submucosas del tubo digestivo
}

\section{¿QUÉ ES UNA LESIÓN SUBMUCOSA EN EL TUBO DIGESTIVO?}

Cuando hablamos de lesiones submucosas (también denominadas lesiones subepiteliales), nos referimos a protrusiones o abultamientos que encontramos en la superficie interna de la pared del tubo digestivo (en el esófago, estómago, intestino delgado, colonrecto). Generalmente, cuando durante la endoscopia encontramos una protrusión, suele tratarse de un pólipo o tumor que nace directamente de la capa más superficial llamada mucosa, sin embargo las lesiones submucosas aparecen por debajo de dicha capa. Por ello, el aspecto de la mucosa superficial es normal, aunque está abultada porque debajo de ella se encuentra la lesión. Podemos entenderlo si imaginamos que debajo de una sábana colocamos una pelota de ping-pong. Veremos un abultamiento esférico, pero la capa superficial (la sábana) es un tejido de aspecto normal. Por lo tanto el término lesión submucosa se refiere solo a la localización de la lesión en la pared del tubo digestivo, pero no indica qué tipo de células la forman.

La mayoría de lesiones submucosas están formadas por tejido muscular, nervioso o neuroendocrino (células nerviosas que producen hormonas). En algunas situaciones un órgano o estructura puede comprimir la pared del tubo digestivo desde el exterior y hacer parecer que se trata de una lesión submucosa. Especialmente en el estómago, la lesión subepitelial más frecuente es el GIST (traducido del inglés significa tumor estromal gastrointestinal); para confirmar el diagnóstico es necesario el estudio histológico (microscópico) en el que se aplica una tinción especial para detectar la existencia de un componente celular denominado c-kit, que se encuentra en el $95 \%$ de los GIST y que, por lo tanto, permite diferenciarlos de otras lesiones submucosas.

\section{¿CÓMO SE ESTUDIAN LAS LESIONES SUBMUCOSAS?}

El diagnóstico definitivo de las lesiones submucosas se consigue con el estudio histológico (observación con un microscopio) de la lesión. Para ello idealmente debería obtenerse material de la lesión durante la endoscopia con una pinza de biopsia. Sin embargo, la localización profunda de estas lesiones supone que si se biopsia solo la capa superficial, se obtenga solo tejido normal. Esto representa uno de los problemas en el estudio de las lesiones submucosas.

El diagnóstico debe hacerse primero por la sospecha durante la endoscopia. La técnica más útil es la ultrasonografía endoscópica (USE) (también llamada ecoendoscopia). Se realiza de manera similar a la endoscopia, empleando sedación para que el paciente no sienta molestias. Permite observar en profundidad las capas del tubo digestivo, determinando en cuál se localiza la lesión, así como observar las características ecográficas y el tamaño, lo que puede ayudar a estimar de qué tipo de lesión se trata y cuál es el mejor tratamiento a aplicar. Mediante la USE se puede tomar material de la lesión para estudio al microscopio, bien por punción y aspiración (llamada PAAF) o con una aguja que corta y recupera un cilindro de tejido (tru-cut). Además esta técnica ayuda a confirmar que real- mente existe una lesión y que no se trata, por ejemplo, de un vaso sanguíneo debajo de la mucosa. En casos concretos, especialmente en las lesiones de mayor tamaño, puede ser necesario realizar una prueba de imagen como un TAC de abdomen.

\section{¿CUÁL DEBE SER EL SEGUIMIENTO Y EL TRATAMIENTO DE LAS LESIONES SUBMUCOSAS?}

La mayoría de las lesiones submucosas no son malignas, pero algunas, sobre todo las de mayor tamaño, sí pueden serlo o tener mayor riesgo de progresar. Existen varias estrategias posibles dependiendo de la localización de la lesión, tamaño, aspecto en la endoscopia y especialmente en la ultrasonografía endoscópica, y de las características del paciente (edad, existencia de enfermedades importantes, síntomas atribuibles a la lesión).

En general, en las lesiones pequeñas $(<1 \mathrm{~cm})$ se intenta tomar biopsias durante la endoscopia, y si la ultrasonografía endoscópica no revela alteraciones sospechosas, suele realizarse el seguimiento habitualmente anual para determinar si se produce un aumento en el tamaño o en las características de la lesión que aconsejen su extirpación. Actualmente existen técnicas endoscópicas que permiten extraer en bloque lesiones del tubo digestivo de forma poco invasiva (mucosectomía, disección submucosa), y representan una alternativa para eliminar la lesión y además poder estudiarla completamente al microscopio, y así llegar a un diagnóstico. En las lesiones del intestino delgado no suele recomendarse el tratamiento local endoscópico porque presentar un mayor riesgo de ser malignas o progresar, y es preferible la extirpación completa quirúrgica.

El tratamiento de las lesiones entre 1 y $2 \mathrm{~cm}$ debe individualizarse, considerando las características de la lesión y del paciente, que debe ser informado de las alternativas diagnósticas y terapéuticas. El grado de aceptación del paciente a las exploraciones de seguimiento, y la ansiedad que pueda generar el sentirse portador de una lesión, en ocasiones sin un diagnóstico de certeza, son factores a tener en cuenta a la hora de decidir el abordaje de estas lesiones. Una alternativa diagnóstica que podría proponerle su especialista sería la realización de una incisión con un bisturí especial mediante endoscopia en la capa superficial para poder tomar biopsias a través de ella, y así tomar la decisión de tratamiento en función del resultado.

En las lesiones de $>2 \mathrm{~cm}$, el tratamiento recomendado es el quirúrgico, ya que el riesgo de que las lesiones sean malignas o progresen es mayor. El tratamiento quirúrgico puede realizarse frecuentemente con técnicas poco invasivas (cirugía laparoscópica), y puede ser suficiente con la extirpación de la lesión y la pared donde se aloja. Sin embargo puede ser necesaria una intervención quirúrgica más amplia. Algunos pacientes con lesiones más agresivas y/o con afectación por la lesión en otros órganos, necesitan ser evaluados por un oncólogo y pudieran requerir tratamiento con fármacos quimioterápicos.

A. Parra-Blanco

Departamento de Gastroenterología. Pontificia Universidad Católica de Chile. Santiago, Chile 